\title{
Deep brain stimulation electrodes may rotate after implantation-an animal study
}

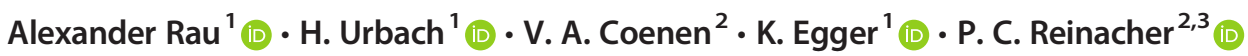 \\ Received: 1 July 2020 / Revised: 13 October 2020 / Accepted: 21 October 2020 / Published online: 30 October 2020 \\ (C) The Author(s) 2020
}

\begin{abstract}
Directional deep brain stimulation (dDBS) electrodes allow to steer the electrical field in a specific direction. When implanted with torque, they may rotate for a certain time after implantation. The aim of this study was to evaluate whether and to which degree leads rotate in the first $24 \mathrm{~h}$ after implantation using a sheep brain model. dDBS electrodes were implanted in 14 sheep heads and 3D rotational fluoroscopy (3D-RF) scans were acquired to visualize the orientation of the electrode leads. Electrode leads were clockwise rotated just above the burr holes $\left(180^{\circ} n=6,360^{\circ} n=6,2\right.$ controls) and 3D-RF scans were again acquired after $3,6,13,17$, and $24 \mathrm{~h}$, respectively. One hundred eighty degree rotated electrodes showed an initial rotation of $83.5^{\circ}$ (range: $35.4^{\circ}-128.3^{\circ}$ ) and a rotation of $114.0^{\circ}$ (range: $57^{\circ}-162^{\circ}$ ) after $24 \mathrm{~h}$. With $360^{\circ}$ torsion, mean initial rotation was $201^{\circ}$ (range: $3.3^{\circ}-321.4^{\circ}$ ) and mean rotation after $24 \mathrm{~h} 215.7^{\circ}$ (range $31.9^{\circ}-334.7^{\circ}$ ), respectively. Direct postoperative imaging may not be accurate for determining the rotation of dDBS electrodes if torque is present.
\end{abstract}

Keywords Directional deep brain stimulation $\cdot$ DBS $\cdot$ Lead orientation $\cdot$ Rotational fluoroscopy

\section{Introduction}

Deep brain stimulation (DBS) is a well-established treatment for several disorders such as Parkinson's disease, tremor, dystonia, and drug-resistant epilepsy. The latest generation of the so-called directional DBS electrodes (dDBS) contains multiple electrode contacts and allows to distribute the stimulation field between the lead segments, thus steering the electrical field in a pre-defined direction. This helps to avoid or reduce inadvertent events by stimulation of adjacent brain regions. To select stimulation parameters which allow for stimulation in a certain direction, the orientation of the dDBS lead in the individual patient brain needs to be known $[1,2]$.

Alexander Rau

alexander.rau@uniklinik-freiburg.de

1 Department of Neuroradiology, Medical Center - University of Freiburg, Faculty of Medicine, University of Freiburg, Breisacher Str. 64, 79106 Freiburg, Germany

2 Department of Stereotactic and Functional Neurosurgery, Medical Center - University of Freiburg, Faculty of Medicine, University of Freiburg, Freiburg, Germany

3 Fraunhofer Institute for Laser Technology, Aachen, Germany
Computed tomography, stereotactic x-ray, and recently 3D rotational fluoroscopy (3D-RF) are accurate imaging modalities to determine the rotation of dDBS [3-6]. They are considered to be very precise (deviation from true orientation: rotational fluoroscopy $\pm 2.44^{\circ}$; CT $-0.6 \pm 1.5^{\circ}$ (range: -5.4 to $4.2^{\circ}$ ); flat-panel CT $5.4^{\circ} \pm 4.1^{\circ}$ (range: $0.4^{\circ}-11.9^{\circ}$ ); stereotactic $\mathrm{x}$-ray $0.0^{\circ} \pm 5.0^{\circ}$ (range: $-12^{\circ}$ to $\left.14^{\circ}\right)$ ).

Flexible dDBS electrodes are implanted into the brain using a stylet, where torsion of the electrode relative to the stylet is conceivable during implantation. The final orientation often shows deviations from $30^{\circ}$ [7] up to $89^{\circ}$ [8] from the intended rotation. This deviation may be caused by a brain shift due to CSF drainage, edema, or pneumocephalus $[9,10]$; however, we hypothesized that it is due to an ongoing torque on the electrode after implantation, too. This ongoing torque may be accentuated, when an intraoperative correction of the rotation by turning the electrode at the skull level is performed $[3,7,11]$. If the electrode continues to rotate after implantation, direct postoperative imaging may be inadequate to obtain the dDBS rotation for stimulation settings $[7,8,11]$.

In order to monitor the dDBS rotation for a certain time, we chose a sheep brain model, as it allows us to implant $10 \mathrm{~cm}$ of electrode length in brain tissue under relatively realistic conditions. 


\section{Methods}

dDBS electrodes were implanted in 15 sheep heads by a stereotactic neurosurgeon (16 years of experience), one electrode per head-nine times Cartesia ${ }^{\mathrm{TM}}$ (Boston Scientific, USA) and six times Infinity ${ }^{\mathrm{TM}}$ (Abbott Neuromodulation, Plano, TX, USA). Implantation was performed via a burr hole trephination and free hand as torsion free as possible. Directly after implantation, the electrodes were fixed with clamps anchored in the bone so that the electrodes could not rotate at this level. A helical CT scan was acquired immediately after implantation in order to check the position (XYZ coordinates) and whether the electrode runs through brain tissue over its entire length (Siemens Somatom Scope, Siemens Healthcare, Forchheim, Germany, voltage $130 \mathrm{kV}$, exposure, $90 \mathrm{mAs}$, pitch factor 0.33 , tilt $0^{\circ}$, slice thickness $1.2 \mathrm{~mm}$, helical mode). An example is given in Fig. 1a.

A 3D rotational fluoroscopy scan (3D-RF) was acquired in order to determine the dDBS rotation. This method has been described previously and selects one of 622 rotational projections, which shows the dDBS orientation clearly [3]. Afterwards, the fixation at the skull level was carefully released and the dDBS was rotated at the skull level by either $180^{\circ}(n=6)$ or $360^{\circ}(n=6)$ and the extracranial part was permanently fixed to the skull using the same technique, immediately after a second 3D-RF run was acquired. Another two dDBS electrodes were fixed after implantation without rotation and served as controls.

3D-RF runs were acquired after 3, 6, 13, 17, and $24 \mathrm{~h}$ and during this period, the sheep heads have carried a distance of $200 \mathrm{~m}$ to simulate the patient's movement and stored at $37^{\circ} \mathrm{C}$.

3D-RF runs were acquired using a flat panel detector $\mathrm{C}$ arm (Allura Xper biplane FD20 20; Philips Healthcare, Best, the Netherlands). The 3D cerebral propeller scan acquires a total of 622 projections within $20.7 \mathrm{~s}$ covering a rotation range of $210^{\circ}$ rotating from a left-sided position over the forehead to a right-sided lateral position (Fig. 1b).

The image data were evaluated using an image viewer capable of showing the acquisition angle (http://clinical. netforum.healthcare.philips.com/global/Explore/ClinicalNews/MRI/Philips-DICOM-Viewer-download-version-R30SP3). Initial rotation, rotation after applied torsion and after 3, $6,13,17$, and $24 \mathrm{~h}$, was evaluated accordingly [3].

\section{Results}

In 14 sheep heads, implantation with a total parenchymal dDBS course was achieved. One sheep head was excluded because of accidental electrode dislocation.

In two controls, only slight deviations from the initial dDBS rotation were observed $\left(1^{\circ}\right.$ and $4^{\circ}$ after $24 \mathrm{~h}$, respectively).

After $180^{\circ}$ torsion, the mean initial rotational deviation was $83.5^{\circ}$ (range: $35.4^{\circ}-128.3^{\circ}$ ), and the mean rotational deviation after $24 \mathrm{~h}$ was $114.0^{\circ}$ (range: $57^{\circ}-162^{\circ}$ ), respectively. Thus, a mean rotational deviation of $30.5^{\circ}$ (range: $14.1^{\circ}-48.2^{\circ}$ ) occurred.

The exact time course over $24 \mathrm{~h}$ is displayed in Table 1 and Fig. 2.

With $360^{\circ}$ torsion, mean initial rotation was $201^{\circ}$ (range: $3.3^{\circ}-321.4^{\circ}$ ), and mean rotational deviation after $24 \mathrm{~h}$ was $215.7^{\circ}$ (range $31.9^{\circ}-334.7^{\circ}$ ), respectively. Thus, a mean rotational deviation of $18.8^{\circ}$ (range: $8.6^{\circ}-35.2^{\circ}$ ) occurred.

\section{Discussion}

When a dDBS electrode is implanted with torque or when the rotation is corrected intraoperatively by rotating it at the burr

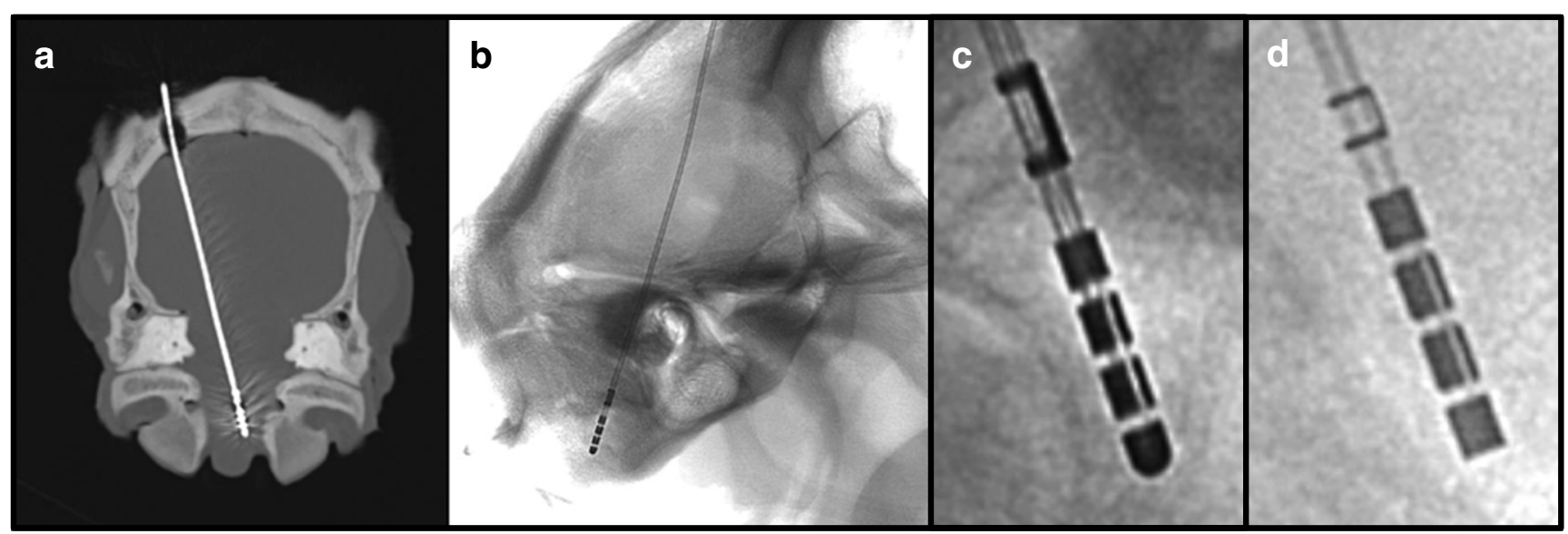

Fig. 1 Imaging modalities in this modal trial. a CT scan after electrode implantation with maximum intensity projection showing a transparenchymal course of the electrode (Cartesia ${ }^{\mathrm{TM}}$ ). b Lateral projection (note the overlap of the meatus acusticus externus) of the
3D-RF with Cartesia ${ }^{\mathrm{TM}}$ implanted. c Excerpt from the 3D-RF, which depicts the so-called iron-sight sign of a Cartesia ${ }^{\mathrm{TM}}$ electrode. This occurs exactly orthogonal to the electrodes orientation - note the c-shaped lead marker. d "Iron-sight" sign of an InfinityTM electrode 
Table 1 Rotational deviation of the implanted electrodes after applied torsion

\begin{tabular}{|c|c|c|c|c|c|c|c|c|c|}
\hline $\begin{array}{l}\text { Sheep } \\
\text { head }\end{array}$ & dDBS & $\begin{array}{l}\text { Applied } \\
\text { torsion }\end{array}$ & $\begin{array}{l}\text { Initial rotational } \\
\text { deviation }\end{array}$ & $3 \mathrm{~h}$ & $6 \mathrm{~h}$ & $13 \mathrm{~h}$ & $17 \mathrm{~h}$ & $24 \mathrm{~h}$ & $\begin{array}{l}\text { Rotational deviation after torsion until } \\
\text { end of follow-up }\end{array}$ \\
\hline 1 & Cartesia $^{\mathrm{TM}}$ & $180^{\circ}$ & $95.7^{\circ}$ & $111.3^{\circ}$ & $121.3^{\circ}$ & $149.0^{\circ}$ & $147.3^{\circ}$ & $153.7^{\circ}$ & $58.0^{\circ}$ \\
\hline 2 & Cartesia $^{\mathrm{TM}}$ & $180^{\circ}$ & $89.1^{\circ}$ & $104.1^{\circ}$ & $108.8^{\circ}$ & & $109.8^{\circ}$ & $108.7^{\circ}$ & $19.6^{\circ}$ \\
\hline 3 & Cartesia $^{\mathrm{TM}}$ & $180^{\circ}$ & $128.3^{\circ}$ & $140.4^{\circ}$ & $142.6^{\circ}$ & $139.7^{\circ}$ & $140.4^{\circ}$ & $142.4^{\circ}$ & $14.1^{\circ}$ \\
\hline 4 & Cartesia $^{\mathrm{TM}}$ & $180^{\circ}$ & $113.4^{\circ}$ & $129.6^{\circ}$ & $131.4^{\circ}$ & $144.3^{\circ}$ & $149.8^{\circ}$ & $161.6^{\circ}$ & $48.2^{\circ}$ \\
\hline 5 & Cartesia $^{\mathrm{TM}}$ & $180^{\circ}$ & Exclusion & Exclusion & Exclusion & Exclusion & Exclusion & Exclusion & Exclusion \\
\hline 6 & Infinity $^{\mathrm{TM}}$ & $180^{\circ}$ & $35.4^{\circ}$ & $44.4^{\circ}$ & $48.4^{\circ}$ & $47.7^{\circ}$ & $61.4^{\circ}$ & $60.7^{\circ}$ & $25.3^{\circ}$ \\
\hline \multirow[t]{2}{*}{7} & Infinity $^{\mathrm{TM}}$ & $180^{\circ}$ & $39.3^{\circ}$ & $41.3^{\circ}$ & $41.0^{\circ}$ & & $47.3^{\circ}$ & $57.0^{\circ}$ & $17.7^{\circ}$ \\
\hline & mean & & $83.5^{\circ}$ & & & & & $114.0^{\circ}$ & $30.5^{\circ}$ \\
\hline 8 & Cartesia $^{\mathrm{TM}}$ & $360^{\circ}$ & $3.3^{\circ}$ & $6.6^{\circ}$ & $6.3^{\circ}$ & $5.5^{\circ}$ & $4.6^{\circ}$ & $31.9^{\circ}$ & $35.2^{\circ}$ \\
\hline 9 & Cartesia $^{\mathrm{TM}}$ & $360^{\circ}$ & $302.3^{\circ}$ & $322.4^{\circ}$ & $332.0^{\circ}$ & & $331.7^{\circ}$ & $334.7^{\circ}$ & $32.4^{\circ}$ \\
\hline 10 & Cartesia $^{\mathrm{TM}}$ & $360^{\circ}$ & $337.0^{\circ}$ & $329.0^{\circ}$ & $318.7^{\circ}$ & & $322^{\circ}$ & $328.4^{\circ}$ & $8.6^{\circ}$ \\
\hline 11 & Infinity ${ }^{\mathrm{TM}}$ & $360^{\circ}$ & $321.4^{\circ}$ & $320.3^{\circ}$ & $330.0^{\circ}$ & $330.7^{\circ}$ & $332^{\circ}$ & $330.3^{\circ}$ & $8.9^{\circ}$ \\
\hline 12 & Infinity $^{\mathrm{TM}}$ & $360^{\circ}$ & $178.7^{\circ}$ & $189.7^{\circ}$ & $197.1^{\circ}$ & & $197.4^{\circ}$ & $197.4^{\circ}$ & $18.7^{\circ}$ \\
\hline \multirow[t]{2}{*}{13} & Infinity ${ }^{\mathrm{TM}}$ & $360^{\circ}$ & $63.1^{\circ}$ & $69.4^{\circ}$ & $64.0^{\circ}$ & $70.5^{\circ}$ & $70.8^{\circ}$ & $72.1^{\circ}$ & $9.0^{\circ}$ \\
\hline & mean & $360^{\circ}$ & $201.0^{\circ}$ & & & & & & $18.8^{\circ}$ \\
\hline 14 & Cartesia $^{\mathrm{TM}}$ & $0^{\circ}$ & $8^{\circ}$ & $11.9^{\circ}$ & $8.9^{\circ}$ & $8.0^{\circ}$ & $10.0^{\circ}$ & $4.1^{\circ}$ & $3.9^{\circ}$ \\
\hline 15 & Infinity ${ }^{\mathrm{TM}}$ & $0^{\circ}$ & $-3.2^{\circ}$ & $1.9^{\circ}$ & $0.2^{\circ}$ & & $3.3^{\circ}$ & $0.8^{\circ}$ & $4.0^{\circ}$ \\
\hline
\end{tabular}

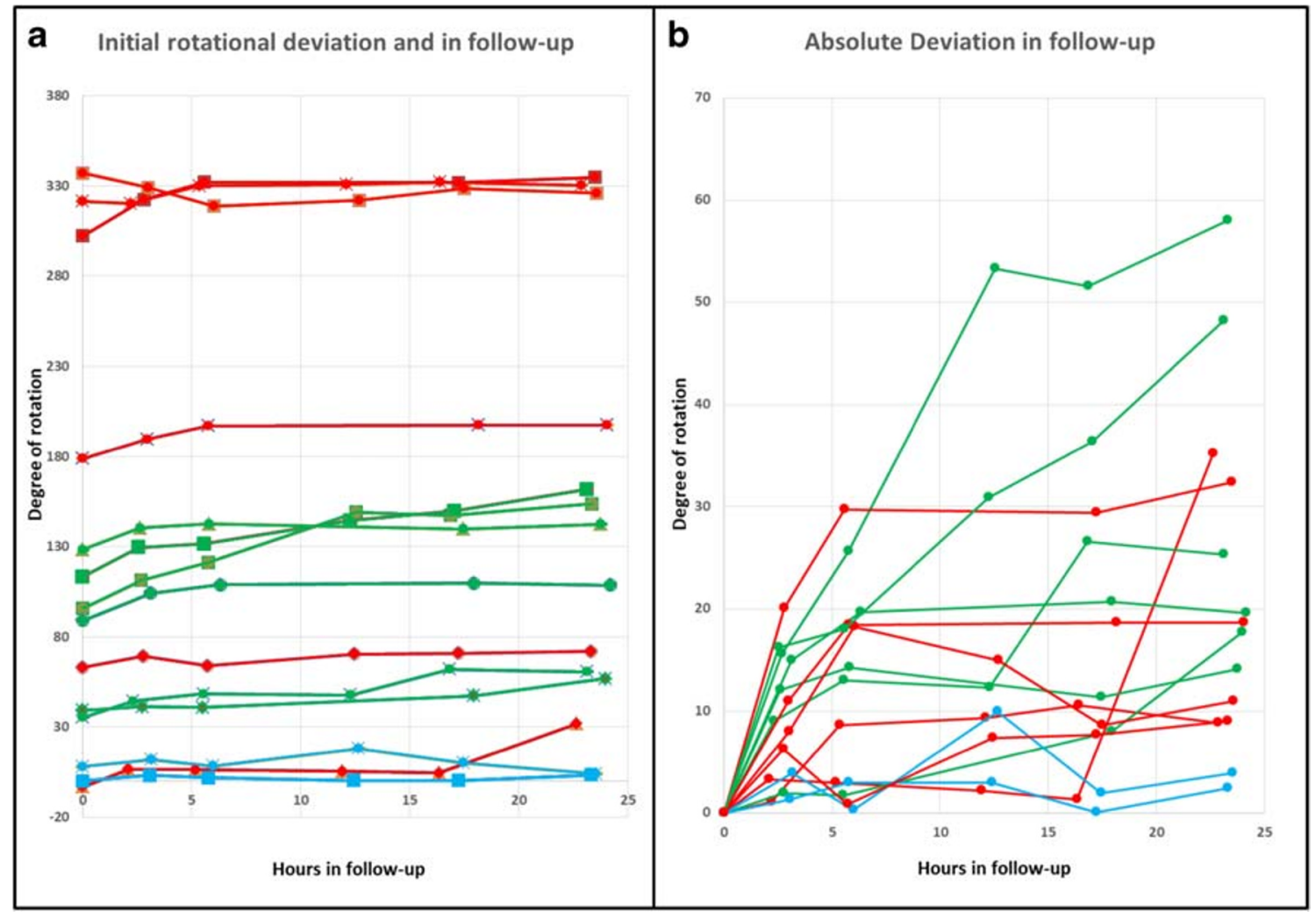

Fig. 2 Rotational deviation of the implanted electrodes after applied torsion. $180^{\circ}$ applied torsion depicted in GREEN, $360^{\circ}$ in RED, and controls $\left(0^{\circ}\right)$ in BLUE. a Initial rotational deviation (time point $0 \mathrm{~h}$ ) and in a follow-up. b Absolute deviation in relation to the rotation after applied torsion 
hole, it takes some time until the rotational torque is transferred to the level of contacts. It has been suggested that there is no rotation over time in leads that do not show rotational deviation during or right after the implantation [12], which might be true in dDBS electrodes implanted without torque. Dembek and colleagues have shown that there is no rotation over time after their first postoperative CT scan $\sim 24-72 \mathrm{~h}$ after implantation [13]. We carried out this investigation to evaluate the immediate time course $(<25 \mathrm{~h})$ of the rotational deviation at the contact level of dDBS electrodes implanted with torsion.

Interestingly, after the applied rotation, not the entire amount of torsion applied was transferred to the level of contacts as it already has been described in the literature that the torsion of the electrode at the skull level is not completely transferred to the level of contacts [3]. Overall, there was a mean transfer of approximately $60 \%$ of the applied torsion. It remains unclear whether this corresponds to the final rotation or whether there was further torque along the electrodes. The extent of rotation in the follow-up-after initial rotation-cannot be predicted as there were no differences between 180 and $360^{\circ}$ rotated dDBS. Interestingly, after $360^{\circ}$ applied torsion, mean rotational deviation was smaller than after $180^{\circ}\left(18.8^{\circ}\right.$ vs. $\left.30.5^{\circ}\right)$, an explanation might be, that at some point, the static friction along the electrode was overcome. The time course is also unpredictable; however, deviations were larger within the first $6 \mathrm{~h}$ following implantation (Fig. 2).

As there are rotational deviations over a time course of at least $24 \mathrm{~h}$, we consider immediate postoperative imaging as suboptimal for determining the dDBS rotation. This might also be true if the implantation is as torsion free as possible since the electrode itself is a rotationally flexible cable [8], thus torque might be present.

Imaging modalities to obtain the dDBS rotation should be both accurate and of low radiation dose.

We are aware of some limitations of this experiment: An intraoperative rotation of $180^{\circ}$ or $360^{\circ}$ is not realistic and was only chosen for this experiment. The sheep model only partially simulates the human condition. However, with respect to body temperature, dDBS length, and parenchymal course, the sheep model is likely the best animal model for this experiment. In vivo human studies are not allowed for this proof of concept study due to radiation exposure and one would not deliberately apply such torque to the leads in a human.

\section{Conclusion}

In order to obtain the exact rotation of directional DBS electrodes, specific imaging should be acquired at the latest possible time point (e.g., on the day of discharge) but earliest $24 \mathrm{~h}$ after implantation. Furthermore, we suggest not to deliberately apply torque to dDBS electrodes during or after implantation.

Authors' contributions All authors contributed to the study conception and design. Material preparation, data collection, and analysis were performed by Alexander Rau and Peter Reinacher. The first draft of the manuscript was written by Alexander Rau and Peter Reinacher and all authors commented on previous versions of the manuscript. All authors read and approved the final manuscript.

Funding Open Access funding enabled and organized by Projekt DEAL.

Availability of data and material (data transparency) The datasets analyzed during the current study are available from the corresponding author on reasonable request.

\section{Compliance with ethical standards}

Conflict of interest P.C.R. has received research support from Else Kröner-Fresenius Foundation, Fraunhofer Foundation (ATTRACT), German Ministry for Economic Affairs and Energy, and the Medical Faculty of the University of Freiburg. He has received personal honoraria for lectures or advice from Boston Scientific, Inomed, Brainlab, and Fraunhofer Foundation, and is a consultant for Boston Scientific. All other authors declare that they have no conflict of interest.

Ethical approval Not applicable.

Informed consent Not applicable.

Code availability (software application or custom code) Not applicable.

Open Access This article is licensed under a Creative Commons Attribution 4.0 International License, which permits use, sharing, adaptation, distribution and reproduction in any medium or format, as long as you give appropriate credit to the original author(s) and the source, provide a link to the Creative Commons licence, and indicate if changes were made. The images or other third party material in this article are included in the article's Creative Commons licence, unless indicated otherwise in a credit line to the material. If material is not included in the article's Creative Commons licence and your intended use is not permitted by statutory regulation or exceeds the permitted use, you will need to obtain permission directly from the copyright holder. To view a copy of this licence, visit http://creativecommons.org/licenses/by/4.0/.

\section{References}

1. Pollo C, Kaelin-Lang A, Oertel MF, Stieglitz L, Taub E, Fuhr P, Lozano AM, Raabe A, Schüpbach M (2014) Directional deep brain stimulation: an intraoperative double-blind pilot study. Brain. 137(7):2015-2026. https://doi.org/10.1093/brain/awu102

2. Steigerwald F, Müller L, Johannes S, Matthies C, Volkmann J (2016) Directional deep brain stimulation of the subthalamic nucleus: a pilot study using a novel neurostimulation device: horizontal current steering in DBS. Mov Disord 31(8):1240-1243. https://doi. org $/ 10.1002 /$ mds.26669

3. Reinacher PC, Krüger MT, Coenen VA, Shah M, Roelz R, Jenkner C, Egger K (2017) Determining the orientation of directional deep brain stimulation electrodes using 3D rotational fluoroscopy. AJNR 
Am J Neuroradiol 38(6):1111-1116. https://doi.org/10.3174/ajnr. A5153

4. Sitz A, Hoevels M, Hellerbach A, Gierich A, Luyken K, Dembek TA, Klehr M, Wirths J, Visser-Vandewalle V, Treuer H (2017) Determining the orientation angle of directional leads for deep brain stimulation using computed tomography and digital x-ray imaging: a phantom study. Med Phys 44(9):4463-4473. https://doi.org/10. $1002 / \mathrm{mp} .12424$

5. Hunsche S, Neudorfer C, Majdoub FE, Maarouf M, Sauner D (2019) Determining the rotational orientation of directional deep brain stimulation leads employing flatpanel computed tomography, Oper. Neurosurg 16(4):465-470. https://doi.org/10.1093/ons/ opy 163

6. Hellerbach A, Dembek TA, Hoevels M, Holz JA, Gierich A, Luyken K, Barbe MT, Wirths J, Visser-Vandewalle V, Treuer H (2018) DiODe: directional orientation detection of segmented deep brain stimulation leads: a sequential algorithm based on CT imaging. Stereotact Funct Neurosurg 96(5):335-341. https://doi.org/10. $1159 / 000494738$

7. Steigerwald F, Matthies C, Volkmann J (2019) Directional deep brain stimulation. Neurotherapeutics 16(1):100-104. Published online 2018 Sep 19. https://doi.org/10.1007/s13311-018-0667-7

8. Dembek TA, Hoevels M, Hellerbach A, Horn A, Petry-Schmelzer JN, Borggrefe J, Wirths J, Dafsari HS, Barbe MT, VisserVandewalle V, Treuer H (2019) Directional DBS leads show large deviations from their intended implantation orientation. Parkinsonism Relat Disord 67:117-121. https://doi.org/10.1016/j. parkreldis.2019.08.017
9. Morishita T, Hilliard JD, Okun MS, Neal D, Nestor KA, Peace D, Hozouri AA, Davidson MR, Bova FJ, Sporrer JM, Oyama G, Foote KD (2017) Postoperative lead migration in deep brain stimulation surgery: incidence, risk factors, and clinical impact. PLoS One 12:e0183711. https://doi.org/10.1371/journal.pone. 0183711

10. van den Munckhof P, Contarino MF, Bour LJ, Speelman JD, de Bie RM, Schuurman PR (2010) Postoperative curving and upward displacement of deep brain stimulation electrodes caused by brain shift. Neurosurgery 67:49-53. https://doi.org/10.1227/01.NEU. 0000370597.44524.6D

11. Hartmann CJ, Fliegen S, Groiss SJ, Wojtecki L, Schnitzler A (2019) An update on best practice of deep brain stimulation in Parkinson's disease. Ther Adv Neurol Disord 12: 1756286419838096. https://doi.org/10.1177/1756286419838096

12. Krueger MT, Naseri Y, Cavalloni F, Reinacher PC, Kägi G, Weber J, Brogle D, Bozinov O, Hägele-Link S, Brugger F (2020) Do directional deep brain stimulation leads rotate after implantation? Acta Neurochir (Wien). https://doi.org/10.1007/s00701-02004568-3 Online ahead of print

13. Dembek T, Asendorf A, Wirths J, Barbe MT, Visser-Vandewalle $\mathrm{V}$, Treuer H. Temporal stability of Lead orientation in directional deep brain stimulation. Preprint

Publisher's note Springer Nature remains neutral with regard to jurisdictional claims in published maps and institutional affiliations. 